\title{
Technique to reduce blood loss during open abdominal myomectomy: transverse or vertical incision?
}

\author{
Ozlem Uzunlar1 ${ }^{\circledR}$, Mujde Can Ibanoglu²* ${ }^{\circ}$, Asli Kaplan ${ }^{3}$
}

\section{SUMMARY}

OBJECTIVE: To determine if there is a difference between uterine incision techniques (vertical vs. transversal) in terms of clinical results. METHODS: All women with leiomyomas who underwent open abdominal myomectomy $(n=61)$ between March and August 2016 at the Gynecology and Obstetrics Clinic at the Women's Health Research and Training Hospital Zekai Tahir Burak were included, and the clinical results were included and prospectively reviewed.

RESULTS: The estimated blood loss during myomectomy increased in the transversal group compared with the vertical group (809.33 \pm 483.34 versus $405.32 \pm 180.95 \mathrm{~mL}, \mathrm{p}<0.001$ ). The average operation duration was $60 \mathrm{~min}$, and the patients got discharged on the second day after surgery. No intergroup statistical differences were observed in the surgical procedure.

CONCLUSIONS: Surgeons should give preference to the most viable incision depending on the size and location of the leiomyoma. KEYWORDS: Gynecologic surgical procedures. Uterine myomectomy. Safety. Ergonomics.

\section{INTRODUCTION}

Uterine leiomyomas are common conditions characterized by the estrogen-dependent benign tumors in women of reproductive age ${ }^{1}$. The leiomyomas may be asymptomatic or may cause bleeding, pain, pelvic pressure, or infertility. The standard treatment for symptomatic leiomyomas is surgical treatment, which is either hysterectomy in women whose age is above the childbearing age or myomectomy in women who wish to preserve fertility and their uterus ${ }^{2}$. Open abdominal myomectomy was described for the first time by Dr. Victor Bonney in 1931 for the women who want to preserve the uterus whether she desires for future fertility or not ${ }^{3}$. Myomectomy is reported to cause more blood loss and to have longer operating hours compared with hysterectomy ${ }^{4}$.

In myomectomy, Pfannenstiel transverse incision is commonly used for the abdominal wall. The next step of the procedure is to make the uterine incision. In a normal uterus, arcuate blood vessels run horizontally and radial vessels penetrate deeply into the myometrium ${ }^{5}$. However, leiomyomas distort normal vascular anatomy and also the vessel structures. The traditional teaching advocates vertical incision during myomectomy to prevent transection of the vascular architecture of the

\footnotetext{
'University of Health Sciences, Ankara Dr. Zekai Tahir Burak Women's Health Practice and Research Center, Department of Obstetrics and Gynecology Ankara, Turkey.

2Etlik Zubeyde Hanim Women's Health and Research Hospital, Department of Obstetrics and Gynecology - Ankara, Turkey.

${ }^{3}$ Ankara City Hospital, Ankara Dr. Zekai Tahir Burak Women's Health Practice and Research Center, Department of Obstetrics and Gynecology Ankara, Turkey.

*Corresponding author: drmujdecan@gmail.com

Conflicts of interest: the authors declare there are no conflicts of interest. Funding: none.

Received on November 07, 2020. Accepted on November 27, 2020.
} 
uterus. However, there is no consensus on the optimal direction of myomectomy incisions.

We designed a randomized prospective study to determine if there is a difference in clinical outcomes regarding the blood loss, operation duration, and hospitalization duration between the vertical and transverse uterine incision techniques. In this prospective analysis of patients who desired future fertility and underwent open abdominal myomectomy, we compared the estimated blood loss during myomectomy, operation duration, and complications of both types of uterine incisions.

\section{METHODS}

This randomized case-control study was conducted in a tertiary care center in Ankara, Turkey between March and August 2016. This study was approved by the institutional review board of the University of Health Sciences, Zekai Tahir Burak Women's Health Care, Education, and Research Hospital (26/06/2014 \#18). All participants gave written informed consent, and the principles of the Declaration of Helsinki were followed.

During the study period, myomectomy procedures were performed to a total of 61 women aged $25-45$ years. The exclusion criteria were infertility, prior myomectomy, leiomyomas localized in submucosa, cervix or broad ligament, women with adnexal masses, congenital uterine abnormality, and women with malignant tumors due to risks of complication and prolonged operation duration. Clinical characteristics and sociodemographic data of the women were recorded. The women were examined and operated by the same operator (OU). Before the surgery, the uterine size was examined by $\mathrm{OU}$ in terms of gestational weeks. The researcher (MCI) attended all cases in order to analyze the operation duration and to calculate blood loss. Surgical sponges and laparotomy packs were weighed dry before surgery and wet immediately after use. Blood loss in surgical sponges was calculated by the following formula: [wet sponge weight $(\mathrm{g})$ - dry sponge weight $(\mathrm{g})$ ] divided by $1.06 \mathrm{~g} / \mathrm{mL}$ (the density of blood) ${ }^{6}$. The total blood loss was calculated according to the total number of surgical sponges $(10 \mathrm{~mL})$, laparotomy packs $(100 \mathrm{~mL})$, and the blood in the vacuum aspirator.

All women were operated under general endotracheal anesthesia, and a Foley catheter was placed inside the bladder. The Pfannenstiel transverse incision was used for all abdominal wall incisions. The abdominal fascia and peritoneal membrane were cut longitudinally and then uterus was visualized. Bistoury and scalpels were used for all incisions. A simple random sampling method was used for choosing control and study groups. In this sampling method, each member of the population had an exactly equal chance of being selected. After randomization, the transverse or vertical uterine incision groups were performed, extending through the myometrium and entire fibroid pseudocapsule. Allis clamps were put on the myometrial edges to expose the leiomyomas, and then leiomyomas were extirpated by grasping them with a single tooth tenaculum. The location, number, and direction of uterine incisions in the cases of multiple leiomyomata depended on their locations and sizes. An effort was made to remove as many fibroids as possible through each uterine incision to minimize the total number of uterine incisions. Multiple incisions were often necessary but the number and size were minimized and performed anteriorly when possible. Towel clamps were used on the leiomyoma for traction as required. All visible and palpable fibroids were removed. The endometrial cavity was stained with diluted methylene blue dye transcervically after the anesthetic induction, immediately preceding the operation to facilitate recognition of cavity entry during surgery and to aid in carefully layered closure of uterine defects. If the uterine cavity was entered, the endometrium was reapproximated with a running 3-0 vicryl suture on a small tapered needle. Myometrial defects were closed with interrupted number 0 vicryl suture before the subsequent uterine incision was carried out. The serosa was reapproximated with a running imbricating suture of 3-0 vicryl, and then the peritoneum, fascia, and skin were closed. Each subject received the routine postoperative care, which included monitoring of the patient's hemodynamic and fluid status, pain control, and reintroducing normal diet and activity.

\section{Statistical analysis}

The statistical analyses were performed by using IBM SPSS Statistics 21 (IBM, Armonk, NY USA). For continuous variables, results were presented as mean \pm standard deviation in parametric data and as median (minimum, maximum) in nonparametric data, and for categorical variables, the results are summarized as frequency and percentages. The normality of the continuous variables was evaluated with the Shapiro-Wilk test. A comparison of continuous variables for the two groups was performed using the Mann-Whitney $U$ test for nonparametric data and independent sample $t$-test for parametric data. Comparisons between two categorical variables were performed using the chi-square analysis. Repeated measures of ANOVA were used to evaluate group differences over three time points (baseline, second hour, and sixth hour). All tests were two-sided, and a $\mathrm{p}<0.05$ was considered to be statistically significant.

\section{RESULTS}

Among the 61 myomectomy operations, 31 women were operated with a vertical uterine incision, and 30 women were operated with a transverse uterine incision in this study. 
The demographic variables (e.g., median age and number of parity) of patients were considered because of their impact on the operation. The size, number, and location of leiomyomas were also identified. The characteristics of the participants and the leiomyomas are presented in Table 1. The two groups were similar regarding the median age, parity, mean leiomyoma diameter, and uterine size. There was one dominant myoma in two groups, but the number of leiomyomas was significantly different from each other. There were significantly more leiomyomas in the transverse incision group than vertical incision group. The most common symptoms were chronic pelvic pain and abnormal uterine bleeding, and no statistically significant differences were observed between the two groups.

The intraoperative blood loss was higher in the transverse incision group compared with the vertical incision group (809.33 $\pm 483.34 \mathrm{~mL}$ versus $405.32 \pm 180.95 \mathrm{~mL}, \mathrm{p}<0.001)$. Table 2 summarizes the operation duration ( $\mathrm{min}$ ), hospitalization duration (days), and total blood loss $(\mathrm{mL})$ during operation. The median operation duration was $60 \mathrm{~min}$, and the patients were discharged on postoperative second day.

The hemoglobin levels are compared in detail in Table 3. In Table 2, no difference was observed between preoperative and postoperative second- and sixth-hour hemoglobin values

Table 1. Demographic and general characteristics of groups.

\begin{tabular}{l|c|c|c} 
& $\begin{array}{c}\text { Vertical incision group } \\
(\mathrm{n}=31)\end{array}$ & $\begin{array}{c}\text { Transverse incision group } \\
(\mathrm{n}=30)\end{array}$ & -value \\
\hline Age, years (median, range) & $39(26-45)$ & $37.5(25-44)$ & 0.058 \\
\hline Parity (median, range) & $2(0-3)$ & $2(0-5)$ & 0.887 \\
\hline Mean myoma diameter, cm (median, range) & $8(5-15)$ & $8(4-13)$ & 0.351 \\
\hline Number of leiomyomas (median, range) & $1(1-4)$ & $1(1-6)$ & 0.010 \\
\hline Uterine size, cm (median, range) & $12(8-18)$ & $12(8-20)$ & 0.485 \\
\hline Chronic pelvic pain & $17(54.8)$ & $15(50)$ & 0.903 \\
\hline Menorrhagia & $22(71)$ & $18(60)$ & 0.528 \\
\hline Location of myomas (n, \%) & & & \\
\hline Anterior & $12(38.7)$ & $16(53.3)$ & 0.374 \\
\hline Posterior & $16(51.6)$ & $14(46.7)$ & 0.896 \\
\hline Fundal & $5(16.1)$ & $6(20)$ & 0.952 \\
\hline Operation duration (min) & $60(45-180)$ & $60(40-200)$ & 0.344 \\
\hline Blood loss $(m L)$ & $400(170-850)$ & $745(170-2200)$ & $<0.001$ \\
\hline Hospital stay duration (days) & $2(2-4)$ & $2(1-7)$ & 0.329 \\
\hline
\end{tabular}

Table 2. Comparison of the two groups in terms of operation duration (min), length of hospital stay (days), and estimated total blood loss $(\mathrm{mL})$ during surgery, pre- and postoperative hemoglobin values.

\begin{tabular}{|c|c|c|c|c|}
\hline & & $\begin{array}{l}\text { Vertical incision group } \\
\text { (mean } \pm \text { standard } \\
\text { deviation) }\end{array}$ & $\begin{array}{c}\text { Transverse incision group } \\
\text { (mean } \pm \text { standard } \\
\text { deviation) }\end{array}$ & $\mathrm{p}$-value \\
\hline \multirow{3}{*}{$\begin{array}{l}\text { Hemoglobin } \\
\text { levels } \\
\text { (g/dL) }\end{array}$} & Preoperative & $11.95 \pm 1.62$ & $11.65 \pm 1.32$ & 0.434 \\
\hline & Postoperative 2 nd hour & $11.13 \pm 1.54$ & $10.36 \pm 1.54$ & 0.056 \\
\hline & Postoperative 6th hour & $10.98 \pm 1.60$ & $10.49 \pm 1.43$ & 0.211 \\
\hline Operation duration (min) & & $60(45-180)$ & $60(40-200)$ & 0.344 \\
\hline Blood loss $(\mathrm{mL})$ & & $405.32(170-850)$ & 809.33 (170-2200) & $<0.001$ \\
\hline $\begin{array}{l}\text { Hospital stay duration } \\
\text { (days) }\end{array}$ & & $2(2-4)$ & $2(1-7)$ & 0.329 \\
\hline
\end{tabular}


Table 3. Comparison of the two groups in terms of difference between second and sixth hours of postoperative hemoglobin levels.

\begin{tabular}{|c|c|c|c|c|c|}
\hline & & $\begin{array}{l}\text { Vertical incision } \\
\text { group } \\
\text { (mean } \pm \text { standard } \\
\text { deviation) }\end{array}$ & $p$-value & $\begin{array}{c}\text { Transverse incision } \\
\text { group } \\
\text { (mean } \pm \text { standard } \\
\text { deviation) }\end{array}$ & $p$-value \\
\hline \multirow{3}{*}{$\begin{array}{l}\text { Hemoglobin } \\
\text { Levels } \\
\text { (g/dL) }\end{array}$} & $\begin{array}{l}\text { Difference between preoperative } \\
\text { and postoperative } 2 \text { nd hour }\end{array}$ & $0.82 \pm 1.25$ & $<0.001$ & $1.29 \pm 0.81$ & $<0.001$ \\
\hline & $\begin{array}{l}\text { Difference between preoperative } \\
\text { and postoperative } 6 \text { th hour }\end{array}$ & $0.97 \pm 1.26$ & $<0.001$ & $1.16 \pm 0.86$ & $<0.001$ \\
\hline & $\begin{array}{l}\text { Difference between postoperative } \\
\text { 2nd hour and 6th hour }\end{array}$ & $0.15 \pm 0.57$ & 0.249 & $-0.12 \pm 0.88$ & 0.365 \\
\hline
\end{tabular}

when the vertical and transverse incision groups were compared. It was found that in the transverse incision group, higher level of blood loss was observed when compared with the vertical incision group. No intraoperative and postoperative complications were reported with transverse or vertical incisions.

\section{DISCUSSION}

The treatment option of leiomyomas depends on the patients' age, future expectation of fertility, symptoms, and size ${ }^{2,7}$. A standard operative technique has not been established in open abdominal myomectomy for the uterine incision.

It has been revealed that the Pfannenstiel incision was preferred three times over multiple laparoscopic incision sites ${ }^{8}$. Mini-laparotomy myomectomy with skin incision $<8 \mathrm{~cm}$ is an alternative surgical method for symptomatic myomas. This surgical technique significantly reduces the operation duration and may even reduce blood loss?. In addition, the operators working in rural areas prefer laparotomy because of the circumstances in which laparoscopic operations may not be performed due to the lack of qualified personnel and the lack of blood transfusion centers and equipment ${ }^{10}$. Robotic myomectomy is feasible for managing large uterine myoma, such as those larger than $10 \mathrm{~cm}$ in diameter, but it takes a reasonable longer operation duration ${ }^{11}$. Therefore, we chose to analyze the open abdominal myomectomy technique.

The myomectomy incision could injure the arterial blood vessels on the leiomyoma surface. The optimal direction of myomectomy incision according to the direction of the blood vessels is unclear. The results of the studies may be contradictory as they are based on the anatomy of the blood vessels in the normal uterus. Most gynecologic surgeons prefer a vertical incision in myomectomy operations, while some surgeons may prefer a transverse incision to protect the horizontal curved arcuate vessels ${ }^{12}$. In a retrospective analysis of the course of arteries in angiography, in patients with symptomatic uterine leiomyomas undergoing uterine artery embolization, it was reported that arterial blood vessels were mostly crossed on the surface of the anterior and posterior fibroids, whereas no dominant pattern was observed in the arterial course of fundal fibroids. It was concluded that the vertical incision would not protect the vascular injuries since approximately $40 \%$ of the vessels cross the middle line 5 . In this context, it can be concluded that the type of uterine incision does not affect the amount of blood loss. Earlier studies have recommended the use of hemostatic procedures during myomectomy to reduce blood loss ${ }^{13}$. Several pharmacological agents (e.g., injection of vasoconstrictors into the incision site, uterotonics, and tranexamic acid) and tourniquets and clamps that occlude the uterine vascular supply are used to decrease the blood loss.

The surgeons often chose their familiar hemostatic technique. There is no consensus on the preferred uterine incision techniques to reduce the blood loss. Blood loss during myomectomy is also correlated with the number, size, and location of leiomyomas. In this prospective study, we found no difference in demographic variables. Although it was shown in the literature that surgical technique affected blood loss during myomectomy, it was found that the uterine size did not affect the blood loss during hysterectomy. Given that myomectomy incisions do not affect the amount of blood loss, the choice of the incision type should depend primarily on the preference of the surgeon. In this study, we studied different incision techniques by randomizing fibroids of similar character.

In this study in which myoma was accessed through two separate incisions made in laparotomic myomectomy, we aimed to compare parameters such as loss of blood, length of stay, and operation duration. However, it was revealed during this study that difficult-to-access myomas such as the posterior and lower segment or cervical leiomyomas can be accessed more easily through transverse incisions. As transverse myomectomy incision makes it easier to approach the fibroids that are difficult to reach, this incision contributes to the shortening of the 
operation duration and the associated risk of anesthesia complications. It also offers individual solutions in the approach to specific cases in training and education hospitals where resident training is provided. But these data are not evidential; rather, it is a fact that we observed at the end of the study. As a secondary outcome, knowing that no intraoperative or early postoperative complications were reported with the two incisions, we may also comment that both incisions are safe and the surgeon should decide the appropriate incision type depending on the size and location of the leiomyoma.

The limitation of this study is that more number of leiomyomas were present in transverse incision groups. The standardization of techniques in this type of study is always a challenge because of the patient-dependent factors. Also, further studies evaluating the outcomes of the type of incision in terms of obstetric outcomes and risk of uterine rupture may be valuable.

\section{CONCLUSIONS}

Both vertical and transverse incision techniques were safe and effective in terms of operation duration and intraoperative blood loss. The surgeons should prefer the most feasible incision depending on the leiomyoma size and localization.

\section{AUTHORS' CONTRIBUTION}

OU: Conceptualization, Data Curation, Formal Analysis, WritingOriginal Draft. MCI: Data Curation, Formal Analysis, WritingOriginal Draft. AK: Formal Analysis, Writing - Original Draft.

\section{REFERENCES}

1. Buttram JuniorVC, Reiter RC. Uterine leiomyomata: etiology, symptomatology, and management. Fertil Steril. 1981;36(4):43345. https://doi.org/10.1016/s0015-0282(16)45789-4

2. TaŞdemir N, Çelik C, Abalı R, Kayalı A, Gül A, Özdamar Ö. Laparoscopic versus abdominal myomectomy postoperative outcomes. Gynecol Obstet Reprod Med. 2014[cited on Jul. 17, 2021];20(1):48-52. Available from: https://www.researchgate. net/publication/273445347_Laparoscopic_Versus_Abdominal_ Myomectomy_Postoperative_Outcomes

3. Charoenkwan K, Iheozor-Ejiofor Z, Rerkasem K, Matovinovic E. Scalpel versus electrosurgery for major abdominal incisions. Cochrane Database Syst Rev. 2017;6(6):CD005987. https:// doi.org/10.1002/14651858.CD005987.pub3

4. Iverson Junior RE, Chelmow D, Strohbehn K, Waldman L, Evantash EG. Relative morbidity of abdominal hysterectomy and myomectomy for management of uterine leiomyomas. Obstet Gynecol. 1996;88(3):415-9. https://doi.org/10.1016/00297844(96)00218-9

5. Discepola F, Valenti DA, Reinhold C, Tulandi T. Analysis of arterial blood vessels surrounding the myoma: relevance to myomectomy. Obstet Gynecol. 2007;110(6):1301-3. https:// doi.org/10.1097/01.AOG.0000290331.95709.26

6. Friedman AJ, Rein MS, Harrison-Atlas D, Garfield JM, Doubilet PM. A randomized, placebo-controlled, double-blind study evaluating leuprolide acetate depot treatment before myomectomy. Fertil Steril. 1989;52(5):728-33. https://doi. org/10.1016/S0015-0282(16)61022-1
7. Petta CA, Aldrighi JM. Qual é a técnica ideal de miomectomia em infertilidade? [Which is the ideal myomectomy technique in infertility?]. Rev Assoc Med Bras (1992). 2000;46(4):301-2. Portuguese. https://doi.org/10.1590/ s0104-42302000000400019

8. Glasser MH. Minilaparotomy myomectomy: a minimally invasive alternative for the large fibroid uterus. J Minim Invasive Gynecol. 2005;12(3):275-83. https://doi.org/10.1016/j.jmig.2005.03.009

9. Huang $M C$, Hsieh $C H$, Su $T H$, Chen $C P$, Yang $T Y$, Wang $K L$, et al. Safety and efficacy of unidirectional barbed suture in mini-laparotomy myomectomy. Taiwan J Obstet Gynecol. 2013;52(1):53-6. https://doi.org/10.1016/j.tjog.2013.01.009

10. Yalinkaya A, Kangal K, Guzel Al, Erdem S. Successful myomectomy of a giant myoma during pregnancy. Gynecol Obstet Reprod Med. 2010 [cited on Jul. 17, 2021];16(3):194-5. Available from: https://www.gorm.com.tr/index.php/GORM/ article/download/371/298

11. Lee $\mathrm{CY}$, Chen IH, Torng PL. Robotic myomectomy for large uterine myomas. Taiwan J Obstet Gynecol. 2018;57(6):796800. https://doi.org/10.1016/j.tjog.2018.10.004

12. Seracchioli R, Manuzzi L, Vianello F, Gualerzi B, Savelli L, Paradisi $R$, et al. Obstetric and delivery outcome of pregnancies achieved after laparoscopic myomectomy. Fertil Steril. 2006;86(1):15965. https://doi.org/10.1016/j.fertnstert.2005.11.075

13. Kongnyuy EJ, van den Broek N, Wiysonge CS. A systematic review of randomized controlled trials to reduce hemorrhage during myomectomy for uterine fibroids. Int J Gynaecol Obstet. 2008;100(1):4-9. https://doi.org/10.1016/j.ijgo.2007.05.050 